\title{
ĐÁNH GIÁ THỰC TRẠNG VÀ TÁC ĐộNG CỦA BIẾN ĐỔI KHÍ HẬU ĐẾn XẦM NHẬP MẶN TỈNH BẾN TRE
}

\author{
Nguyễn Văn Đào ${ }^{1}$, Phạm Thị Thanh Bình ${ }^{2}$
}

Tóm tắt: Bến Tre là tỉnh ven biển, nơi có 4 cửa sông chảy ra biển nên thuờng xuyên chịu ảnh huởng của xâm nhập mặn trong mùa khô. Nghiên cứu được thực hiện nhằm muc tiêu đánh giá thưc trạng và tác động của biến đổi khi hậu (BĐKH) đến xâm nhập mặn trên địa bàn tỉnh Bến Tre theo Kịch bản BĐKH và nước biển dâng (NBD) tới năm 2050. Nghiên cứu thống kê, phân tích chuỗi số liệu đo mặn tù năm 2000-2016 của 6 trạm đo mặn trên địa bàn để đánh giá hiện trạn xâm nhập mặn tại tỉnh Bến Tre; đồng thời sư dụng mô hình thủy lực MIKE11 diến toán ảnh hưởng của BĐKH đến xâm nhập mặn tỉnh Bến Tre trong twơng lai theo kịch bản BĐKH và NBD năm 2016. Kết quả thống kê đã chỉ ra rằng trong giai đoạn 2000 - 2016, tình hình xâm nhập mặn tại tỉnh Bến Tre trong 6 tháng đầu năm có xu thế tăng ở hầu hết các trạm. Xét theo tùng tháng, xu thế tăng được thể hiện chủ yếu, trong đó 100\% trương hơp đỉnh mạn $S_{\text {max }}$ tăng; 91\% truờng hơp chân mặn $S_{\text {min }}$ tăng, 3\% truờng hơp $S_{\text {min }}$ giảm và $6 \%$ trương hợp không đổi. Xu thế tăng thể hiện rõ nét trong các tháng I, II, III. Dưới tác động của BĐKH và nước biển dâng, mặn có xu thế ăn sâu hơn dọc các sông vào đất liền. Mặn $1 \%$ có khả năng ăn sâu vào 55 km trên sông Cổ Chiên, 65 km trên sông Hàm Luông, 68 km trên sông Tiền Giang; mặn 5\%o có khả năng ăn sâu vào 42 km trên sông Cổ Chiên, 44 km trên sông Hàm Luông, 44 56 km trên sông Tiền Giang.

Từ khóa: Biến đổi khi hậu, nước biển dâng, xâm nhập mặn, Tỉnh Bến Tre, mô hình toán, MIKE11.

Ban Biên tập nhận bài: 10/2/2019 Ngày phản biện xong: 15/03/2019 Ngày đăng bài: 25/04/2019

\section{Giới thiệu chung}

Xâm nhập mặn là quy luật tự nhiên ở các khu vực, lãnh thổ có vùng cửa sông giáp biển và là một trong 19 loại hình thiên tai được quy định cụ thể tại Luật phòng, chống thiên tai. Bến Tre nằm ở hạ lưu sông Cửu Long, được hình thành bởi cù lao An Hoá, cù lao Bảo, cù lao Minh, tiếp giáp biển Đông với chiều dài đường biển khoảng $65 \mathrm{~km}$. Trong những năm qua, Bến Tre đã chịu nhiều ảnh hưởng của BĐKH như nhiệt độ trung bình có xu hướng tăng lên, lượng mưa nhiều vùng giảm rõ rệt, mực nước biển dâng cao, nhiều năm xảy ra hạn hán nặng như các năm 2004, 2016, 2017... Trở ngại đáng kể trong nông nghiệp là vào mùa khô, lượng nước từ thượng nguồn đổ về giảm nhiều và gió "Chướng" mạnh đưa nước biển lấn sâu vào nội địa, làm nhiễm mặn đất, ảnh hưởng đến năng suất cây trồng đối với các huyện gần phía biển và ven biển, đã làm ảnh hưởng lớn đến kinh tế-xã hội của tỉnh.

Do tính chất quan trọng của hiện tượng xâm nhập mặn có liên quan đến hoạt động kinh tế-xã hội của nhiều quốc gia nên vấn đề tính toán và nghiên cứu đã được đặt ra từ lâu. Mục tiêu chủ yếu của công tác nghiên cứu là nắm được quy luật của quá trình này để phục vụ các hoạt động kinh tế-xã hội, an ninh-quốc phòng vùng cửa sông như ở các nước như Mỹ, Anh, Hà Lan, Nhật,... từ khoảng 40 - 50 năm trở lại đây. Các phương pháp cơ bản được thực hiện bao gồm: Thực nghiệm (dựa trên số liệu quan trắc) và mô phỏng quá trình bằng các mô hình toán.

Các phương pháp tính toán xâm nhập mặn đầu tiên thường sử dụng bài toán một chiều khi kết hợp với hệ phương trình Saint-Venant. Những mô hình mặn 1 chiều đã được xây dựng do nhiều tác giả trong đó có Ippen và Harleman (1971) [13]. Giả thiết cơ bản của các mô hình

${ }^{1}$ Liên đoàn Khảo sát khí tượng thủy văn

${ }^{2}$ Trung tâm Trắc đạc bản đồ biển, Tổng cuc Biển và Hải đảo Việt Nam

Email:daotvmt@gmail.com 
này là các đặc trưng dòng chảy và mật độ là đồng nhất trên mặt cắt ngang. Mặc dù điều này khó gặp trong thực tế nhưng kết quả áp dụng mô hình lại có sự phù hợp khá tốt, đáp ứng được nhiều mục đích nghiên cứu và tính toán mặn. Uu thế đặc biệt của các mô hình loại một chiều là yêu cầu tài liệu vừa phải và nhiều tài liệu đã có sẵn trong thực tế.

Năm 1971, Prichard đã dẫn xuất hệ phương trình 3 chiều để diễn toán quá trình xâm nhập mặn nhưng nhiều thông số không xác định được [16]. Hơn nữa mô hình 3 chiều yêu cầu lượng tính toán lớn, yêu cầu số liệu quá chi tiết trong khi kiểm nghiệm nó cũng cần có những số liệu đo đạc chi tiết tương ứng. Vì vậy các nhà nghiên cứu buộc phải giải quyết bằng cách trung bình hoá theo 2 chiều hoặc 1 chiều. Sanker và Fischer, Masch (1970) và Leendertee (1971) đã xây dựng các mô hình 2 chiều và 1 chiều trong đó mô hình 1 chiều có nhiều ưu thế trong việc giải các bài toán phục vụ yêu cầu thực tế tốt hơn [15]. Các nhà khoa học cũng thống nhất nhận định rằng, các mô hình 1 chiều thường hữu hiệu hơn các mô hình sông đơn và mô hình hai chiều. Chúng có thể áp dụng cho các vùng cửa sông có địa hình phức tạp gồm nhiều sông, kênh nối với nhau với cấu trúc bất kỳ.

Nghiên cứu xâm nhập mặn tại Việt Nam đã được quan tâm từ những năm 1960 khi bắt đầu tiến hành quan trắc độ mặn ở hai vùng đồng bằng sông Hồng và ĐBSCL. Khởi đầu là các dự án, công trình nghiên cứu, tính toán của Ủy hội sông Mê Công (1973) về xác định ranh giới xâm nhập mặn theo phương pháp thống kê trong hệ thống kênh rạch thuộc 9 vùng cửa sông thuộc ĐBSCL [14]. Các kết quả tính toán từ chuỗi số liệu thực đo đã lập nên bản đồ đẳng trị mặn với hai chỉ tiêu cơ bản $1 \%$ và $4 \%$ cho toàn khu vực đồng bằng trong các tháng từ tháng 12 đến tháng 4 . Viện Khoa học KTTV và Môi trường (2010) [10] đã tiến hành xây dựng các kịch bản dựa trên cơ sở kịch bản $\mathrm{BĐKH} \mathrm{(A2,} \mathrm{B2)} \mathrm{đến} \mathrm{năm} 2050$ kết hợp với các kịch bản phát triển lưu vực sông Mê Công, đồng thời phân tích các tác động của $\mathrm{BĐKH}$ đến dòng chảy vào Việt Nam, cụ thể là dòng chảy năm, dòng chảy mùa lũ, dòng chảy mùa cạn, diễn biến ngập lụt và xâm nhập mặn. Dự án đã sơ bộ xác định những tác động tiềm tàng của $\mathrm{BĐKH}$ đến tài nguyên nước ở ĐBSCL và đề xuất các giải pháp tổng thể ứng phó với $\mathrm{BĐKH}$ và nước biển dâng. Trung tâm Thẩm định-Tư vấn Tài nguyên nước, Cục Quản lý Tài nguyên (2012-2013) [8] đã phân tích diễn biến mặn ở các sông, các vùng trong những năm điển hình; xác định được sự giảm nhỏ của dòng chảy từ thượng lưu đổ về có ảnh hưởng quyết định đến độ lớn và chiều dài xâm nhập mặn; phân tích những yếu tố ảnh hưởng chính đến xâm nhập mặn ở ĐBSCL; xây dựng các loại bản đồ xâm nhập mặn thời kỳ 1991-2012. Ngoài ra còn có chương trình Dự báo độ mặn nền trên các sông chính trong mùa khô (từ tháng 1-6 hằng năm) vùng ven biển ĐBSCL thực hiện bởi Viện KHTL Miền Nam, dự báo độ mặn nền trên hệ thống sông chính vùng ven biển ĐBSCL sử dụng phần mềm HydroGis và MIKE11 [4-6], [11-12].

Tóm lại, các nghiên cứu và dự án trên chủ yếu tập trung đánh giá hiện trạng xâm nhập mặn, xác định nguyên nhân gây xâm nhập mặn, đánh giá tác động ảnh hưởng của xâm nhập mặn đến phát triển nông-lâm ngư nghiệp các tỉnh vùng ven biển ĐBSCL, đề ra các biện pháp công trình ứng phó với xâm nhập mặn. Tuy nhiên các nghiên cứu trên đều thực hiện từ những năm 2014 trở về trước, số liệu chưa được cập nhật (sử dụng số liệu quan trắc đến năm 2010), đặc biệt là số liệu các năm 2015, 2016 là những năm xảy ra xâm nhập mặn khốc liệt ở các tỉnh ven biển ĐBSCL; đồng thời các nghiên cứu cũng chưa chỉ ra sự biến đổi của xâm nhập mặn trong tương lai theo kịch bản $\mathrm{BBĐKH}$ và NBD mới nhất. Trước thực trạng đó, nhận thấy trong vấn đề nghiên cứu BĐKH, nổi bật lên bài toán đánh giá tác động của BĐKH đến xâm nhập mặn ở tỉnh Bến Tre nói riêng (sự nóng lên toàn cầu, thay đổi lượng mưa và mực nước biển dâng có phải là các nhân tố chính ảnh hưởng đến xâm nhập mặn hay không). Câu hỏi khoa học đặt ra là các yếu tố quá trình xâm nhập mặn có biến đổi như thế nào trong thời gian trước đây? Biến đổi trong tương 


\section{BÀI BÁO KHOA HỌC}

lai ra sao dưới tác động của $\mathrm{BĐKH}$ là hết sức cần thiết.

Bài báo này trình bày kết quả đánh giá hiện trạng xâm nhập mặn tỉnh Bến Tre trong đó có cập nhật và sử dụng số liệu mặn mới cập nhật cho tới năm 2016, đồng thời đánh giá sự thay đổi của xâm nhập mặn dưới tác động của $\mathrm{B} Đ K H$ và NBD tới năm 2050.

\section{Phương pháp nghiên cứu và tài liệu thu thập}

\subsection{Phương pháp nghiên cứu}

Nghiên cứu sử dụng phương pháp thống kê để đánh giá và làm rõ tác động của $\mathrm{B} Đ K H$ đến đặc trưng xâm nhập mặn trên địa bàn tỉnh Bến Tre. Để dự tính các tác động của BĐKH tới tình hình xâm nhập mặn trong tương lai, nghiên cứu sử bộ mô hình thuỷ động lực MIKE11 được DHI Water\& Environment phát triển để mô phỏng quá trình xâm nhập mặn trong tương lai tại tỉnh Bến Tre.

Các dữ liệu khí tượng, thủy văn, dữ liệu địa hình, mạng lưới sông, mặt cắt lòng sông cũng như các dữ liệu nền khác được đưa vào mô-đun thủy lực $\mathrm{HD}$, sau quá trình hiệu chỉnh, kiểm định các thông số thủy lực sẽ ra kết quả là trạng thái thủy lực của toàn sông. Kết quả chạy mô hình thủy lực $\mathrm{HD}$ và dữ liệu mặn là số liệu đầu vào của mô-đun lan truyền chất $\mathrm{AD}$, thông qua hiệu chỉnh, kiểm định thông số lan truyền chất sẽ có kết quả lan truyền mặn. Từ các kết quả trên, kết hợp với các kịch bản $\mathrm{BĐKH} \mathrm{và} \mathrm{nước} \mathrm{biển} \mathrm{dâng}$ được lựa chọn của Bộ Tài nguyên và Môi trường sau khi chạy mô hình với bộ thông số chuẩn sẽ ra được các kết quả dự báo theo yêu cầu.

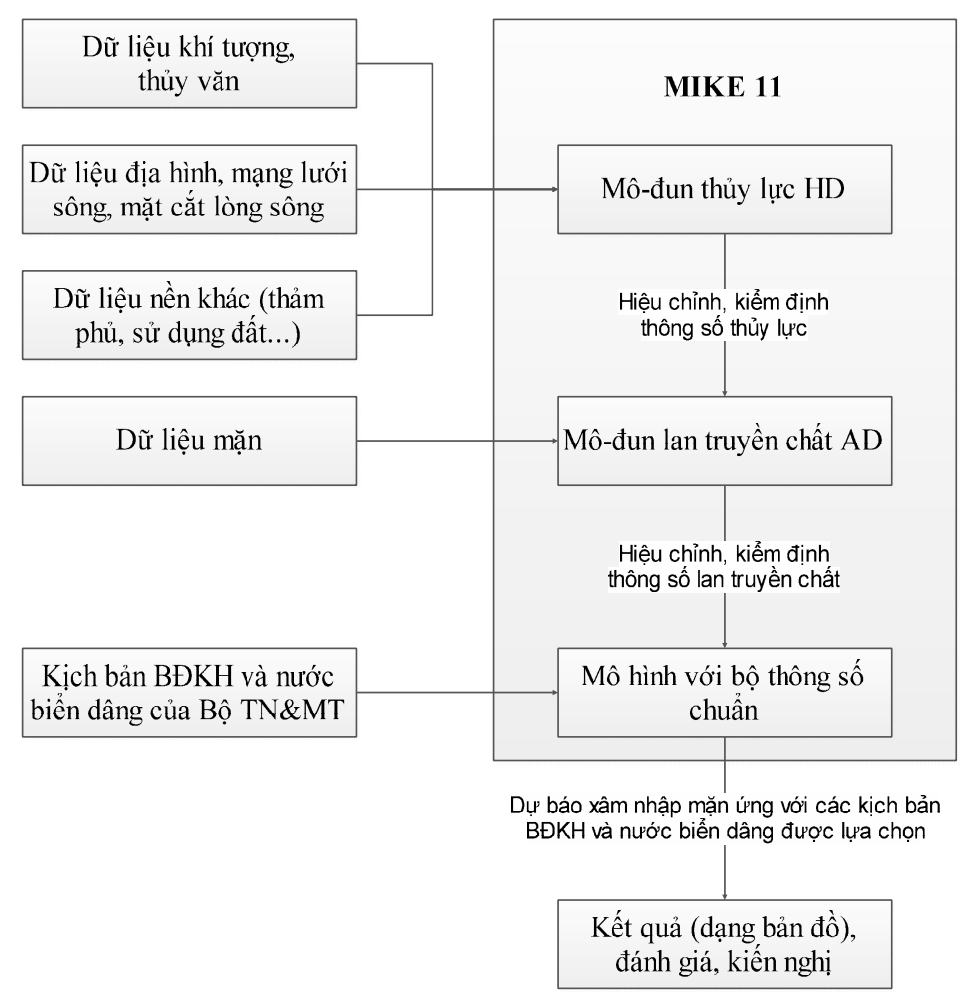

Hình 1. So đồ tính toán xâm nhập mặn theo Kịch bản BĐKH và NBD năm 2016

\subsection{Số liệu phục vụ nghiên cứu}

- Số liệu sơ cấp: Số liệu được thu thập cụ thể như sau: Khu vực tỉnh Bến Tre và lân cận có 03 trạm khí tượng đo đầy đủ các yếu tố; 04 trạm thủy văn cấp I đo đầy các yếu tố trong đó có mực nước, lưu lượng nước và lưu lượng chất lơ lửng trong nước sông và 02 trạm thủy văn cấp 3 đo mực nước sông được lựa chọn để phân tích đặc điểm mưa, nhiệt độ, mực nước đỉnh lũ, lưu lượng lũ, tổng lượng dòng chảy trên sông. Số liệu của 
9 trạm KTTV nêu trên là các tài liệu sơ cấp dùng để tính toán trong bài báo. Số liệu do Đài KTTV khu vực Nam Bộ cung cấp đã qua chỉnh lý, đủ độ tin cậy, là cơ sở trong tính toán kịch bản $\mathrm{BĐKH}$ về lượng mưa, nhiệt độ, mực nước lũ, tổng lượng lũ và các đặc trưng dòng chảy khác trong nghiên cứu này.

+ Số liệu về nhiệt độ: Bao gồm số liệu về nhiệt độ trung bình ngày của các trạm khí tượng: Ba Tri, Mỹ Tho từ năm 1984 đến năm 2016, Càng Long từ năm 1986 đến 2016.

+ Số liệu về lượng mưa: Bao gồm số liệu về tổng lượng mưa của các trạm: Chợ Lách, Mỹ Hóa, An Thuận, Bến Trại, Bình Đại (tỉnh Bến Tre) từ năm 1984 đến năm 2014.

+ Số liệu lưu lượng nước: Quan trắc được tại các trạm thủy văn Tân Châu (tỉnh An Giang), Châu Đốc (tỉnh An Giang), từ năm 1996 đến năm 2016.

+ Số liệu mực nước kiệt: Bao gồm số liệu về mực nước nhỏ nhất năm quan trắc được tại các trạm thủy văn Tân Châu (tỉnh An Giang), Châu Đốc (tỉnh An Giang), Chợ Lách, Mỹ Hoá, An Thuận, Bình Đại, Bến Trại (tỉnh Bến Tre) từ năm 1996 đến năm 2016.

+ Số liệu xâm nhập mặn: Bao gồm số liệu 6 trạm mặn thực đo thuộc tỉnh Bến Tre: An Thuận, Bến Trại, Bình Đại, Hương Mỹ, Lộ Thuận và Sơn Đốc.

- Các số liệu thứ cấp:

+ Số liệu mô phỏng thời kỳ cơ sở 1986 - 2005 và dự tính khí hậu giai đoạn 2016 đến 2050 bằng mô hình PRECIS độ phân giải $25 \mathrm{~km}$ x $25 \mathrm{~km}$, bao gồm số liệu về nhiệt độ và lượng mưa của 22 trạm khí tượng vùng ĐBSCL [7]. Các số liệu này là số liệu đầu vào dùng trong mô hình thủy lực MIKE11 để dự tính các đặc trưng xâm nhập mặn trên địa bàn tỉnh Bến Tre trong tương lai.
- Số liệu về điều kiện tự nhiên, kinh tế xã hội tỉnh Bến Tre năm 2015 được trích dẫn và sử dụng từ Niên giám thống kê 2016 do Tổng cục Thống kê, Bộ Kế hoạch và đầu tư phát hành [9].

- Các bản đồ sử dụng trong nghiên cứu là tài liệu thứ cấp được trích dẫn từ:

+ Báo cáo tổng kết nhiệm vụ khảo sát mặn năm 2016. Đài KTTV khu vực Nam Bộ (2016).

+ Báo cáo tổng kết đề tài nghiên cứu khoa học và công nghệ cấp Nhà nước "Nghiên cứu ảnh hưởng của biến đổi khí hậu đến sự biến đổi tài nguyên nước Đồng bằng sông Cửu Long”. Trần Hồng Thái, Viện Khoa học KTTV và BĐKH (2014) [7].

\section{Kết quả và thảo luận}

\section{1. Đánh giá tình hình xâm nhập mặn giai đoạn tù̀ năm 2000 - 2016}

Trong 6 trạm đo mặn đại diện cho khu vực tỉnh Bến Tre, có 3 trạm nằm ở vị trí cửa sông (An Thuận, Bến Trại và Bình Đại) và 3 trạm nằm ở sâu hơn về phía thượng lưu (Hương Mỹ, Lộc Thuận và Sơn Đốc). Kết quả tính toán chuẩn sai độ mặn lớn nhất (Smax) tháng trong giai đoạn 2000 - 2016 tại 6 trạm này được thể hiện trên Hình 2. Theo đó, diễn biến độ mặn giữa 6 trạm có tính tương đồng, cho thấy xu thế biến đổi mặn giống nhau trên cả 3 nhánh sông: Hàm Luông, Cổ Chiên và Cửa Đại, tuy nhiên sông Hàm Luông bị nhiễm mặn cao hơn, tiếp đó là Cửa Đại và sông Cổ Chiên.

Kết quả cũng cho thấy, các năm có Smax nhỏ hơn nhiều so với TBNN là năm 2000, 2001, 2003, 2006, 2008, 2009, 2012, 2014; những năm có Smax lớn hơn nhiều so với TBNN là năm 2004, 2005, 2007, 2010, 2013, 2015, 2016. Năm 2016 là năm có xâm nhập mặn lớn nhất xuất hiện tháng III, có giá trị lớn hơn TBNN đến $8 \%$ ở tất cả các trạm (Bảng 1, Hình 3). 
Chuẩn sai Smax tháng trạm An Thuận
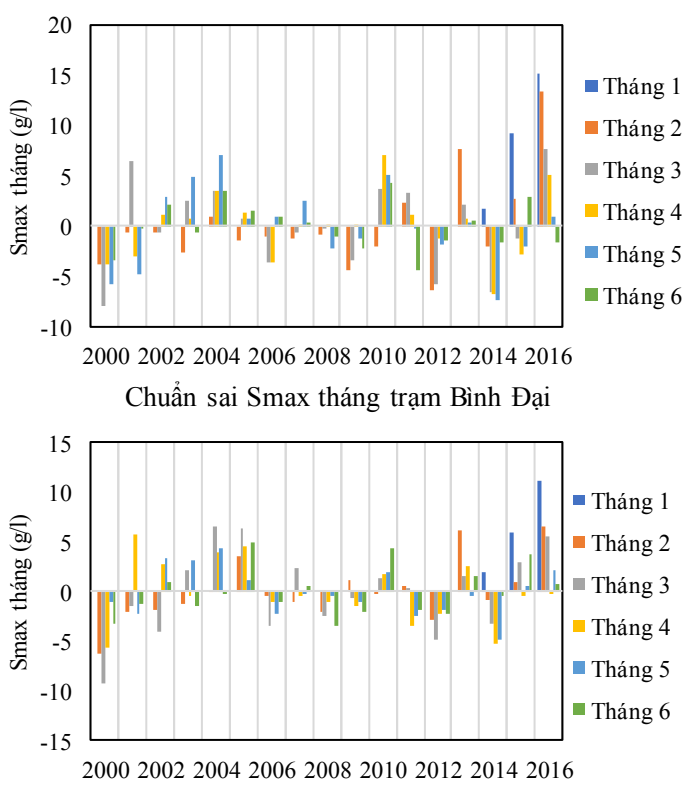

Chuẩn sai Smax tháng trạm Lộc Thuận

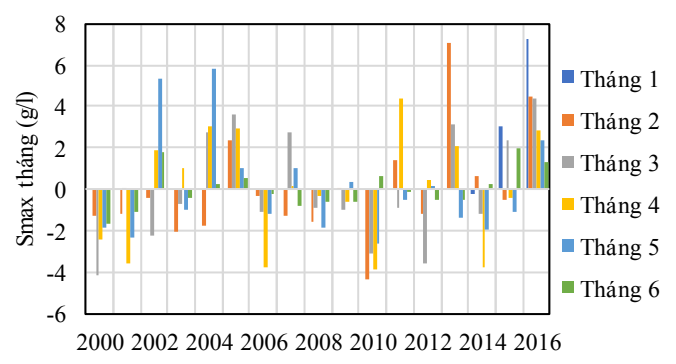

Chuẩn sai Smax tháng trạm Bến Trại

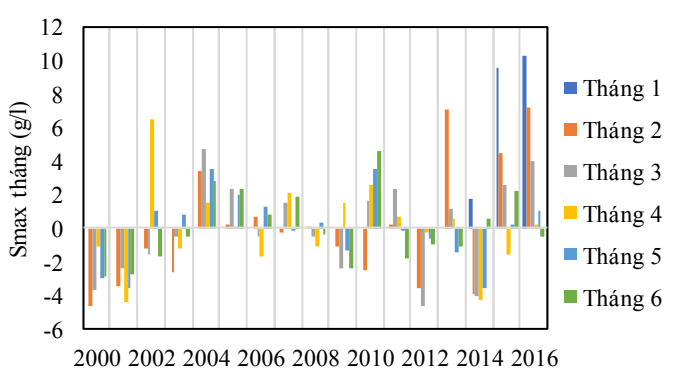

Chuẩn sai Smax tháng trạm Hương Mỹ

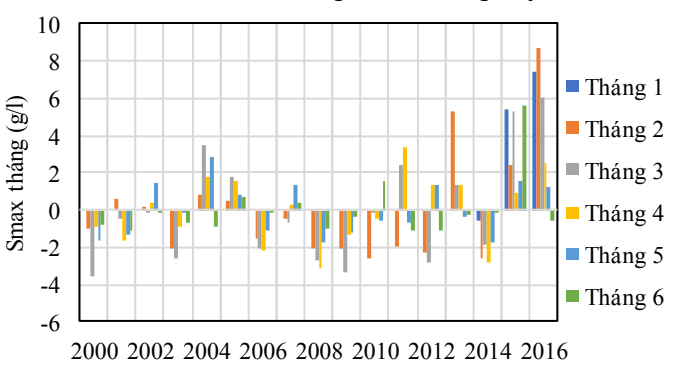

Chuẩn sai Smax tháng trạm Sơn Đốc

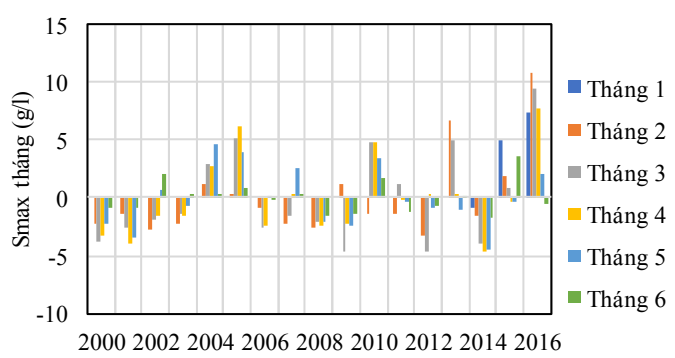

Hình 2. Độ lệch chuẩn của Smax tháng giai đoạn 2000-2016 tại các trạm: An Thuận, Bến Trại, Bình Đại, Hương Mỹ, Lộc Thuận, Sơn Đốc

Bảng 1. Bảng thống kê đỉnh mặn thời đoạn 2000 - 2016

(Đon vị: $g / l$ )

\begin{tabular}{cccccccc}
\hline Năm & An Thuận & Bến Trại & Bình Đại & Hương Mỹ & Lộc Thuận & Sơn Đốc \\
\hline 2000 & 12 & 10 & 8,8 & 0 & 5,1 & 3,5 \\
2001 & 23 & 9,3 & 18,8 & 4 & 7,5 & 3,5 \\
2002 & 17 & 17,6 & 15,7 & 4,5 & 10 & 5,2 \\
2003 & 19,1 & 11,2 & 15 & 3,2 & 8,6 & 5,2 \\
2004 & 20,1 & 16,4 & 19,4 & 7,9 & 10,6 & 9,5 \\
2005 & 17,3 & 14,1 & 19,2 & 6,2 & 11 & 12,9 \\
2006 & 13,1 & 11,3 & 12 & 2,4 & 6,3 & 4,7 \\
2007 & 16,1 & 13,3 & 15,3 & 4,4 & 10,2 & 7 \\
2008 & 16,575 & 11,3 & 11,85 & 1,725 & 7,2 & 4,2 \\
2009 & 15,8 & 12,6 & 12,2 & 2,8 & 6,9 & 4,6 \\
2010 & 22,875 & 13,6 & 14,8 & 4,35 & 4,35 & 11,45 \\
2011 & 20 & 14,025 & 13,3 & 7,475 & 11,9 & 7,275 \\
2012 & 14,6 & 10,775 & 10,775 & 5,425 & 8 & 7,1 \\
2013 & 19,35 & 16,125 & 15,525 & 8,125 & 11,7 & 11,225 \\
2014 & 10,125 & 7,675 & 9,6 & 2,575 & 6,2 & 2,175 \\
2015 & 15,325 & 14,3 & 15,975 & 9,775 & 9,775 & 6,925 \\
2016 & 24,975 & 16,2 & 18,5 & 11,625 & 11,775 & 15,6 \\
\hline
\end{tabular}




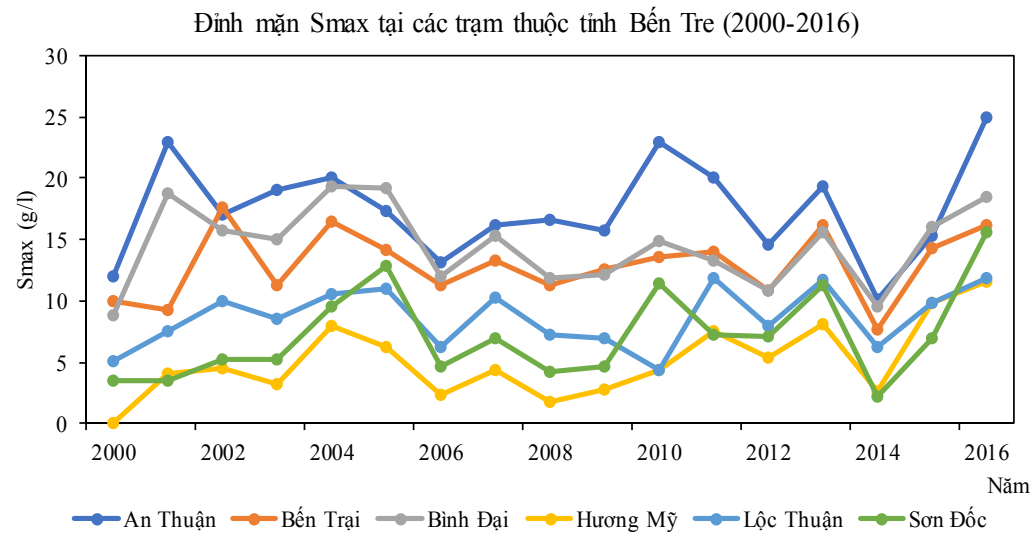

Hình 3. Đưòng quá trình Smax cho 6 trạm tại tỉnh Bến Tre thời đoạn 2000-2016

\subsection{Dụ tính xâm nhập mặn trên địa bàn} tỉnh Bến Tre theo Kịch bản BĐKH và NBD đến 2050

a) Xây dưng mô hình thủy lục, khuếch tán

Để đánh giá tác động của BĐKH tới quá trình xâm nhập mặn trên sông tại tỉnh Bến Tre, nghiên cứu tiến hành xây dựng mô hình MIKE 11 trong đó sử dụng mô-đun HD để mô phỏng trạng thái thủy lực và mô-đun $\mathrm{AD}$ để mô phỏng quá trình lan truyền mặn trên toàn hệ thống sông.
Trong tính toán mô hình 1 chiều, từ hệ thống mặt cắt và mạng lưới của những nghiên cứu trước đây, mạng lưới sông Cửu Long [2-3] được duy trì sử dụng và có xem xét lược bỏ những sông không nằm trong phạm vi nghiên cứu. Các kênh nội đồng cũng không được xét đến do hạn chế về mặt số liệu thu thập được. Sơ đồ mạng thủy lực cùng các vị trí và điều kiện biên được thể hiện trên hình 4.

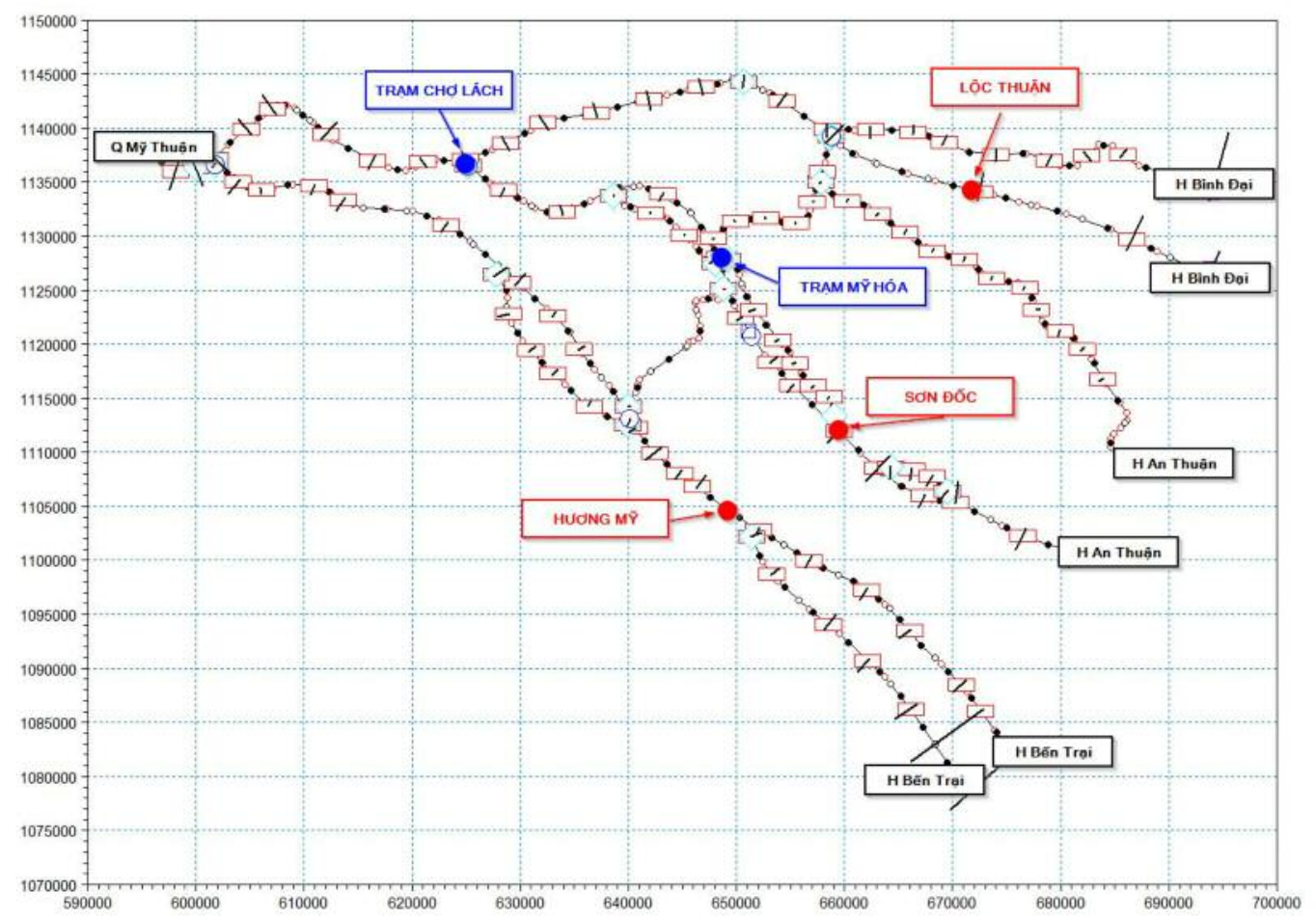

Hình 4. So đồ mô phỏng thủy lực và truyền mặn cho hệ thống sông Tiền Giang tại Bến Tre 


\section{BÀI BÁO KHOA HỌC}

Lưu lượng tại trạm thủy văn Mỹ Thuận được sử dụng làm biên trên cho mạng thủy lực. Tương ứng với các biên dưới là quá trình triều thực đo tại các trạm đặt ngay cửa biển bao gồm: Bến Trại (sông Cổ Chiên), An Thuận (sông Hàm Luông) và Bình Đại (Cửa Đại).

Với tài liệu thực tế còn hạn chế về số liệu thực đo hơn nữa nhằm đáp ứng yêu cầu của bài toán mặn và thủy lực nên các biên kiểm tra được thực hiện tại các trạm sau:

- Trạm kiểm tra mực nước: Mỹ Hóa và Chợ Lách.
- Trạm kiểm tra mặn: Hương Mỹ, Sơn Đốc và Lộc Thuận.

b) Hiệu chinh, kiểm định mô-đun thủy lực 1 chiều

Đối với mô hình MIKE 11 trong nghiên cứu này, việc hiệu chỉnh tham số thủy lực được tiến hành trong thời đoạn từ $01 / 4 / 2010$ đến ngày 30/4/2010. Với bộ thông số thủy lực đã được hiệu chỉnh cho năm 2010, để đảm báo tính ổn định của mô hình, bộ thông số này tiếp tục được kiểm định lại cho thời đoạn từ ngày $01 / 3 / 2016$ đến ngày 31/3/2016 (Bảng 2).

Bảng 2. Thống kê các chỉ tiêu đánh giá kết quả hiệu chỉnh, kiểm định thủy lục

\begin{tabular}{cccccc}
\hline \multirow{2}{*}{ STT } & \multirow{2}{*}{ Các chỉ tiêu } & \multicolumn{2}{c}{ Mỹ Hóa } & \multicolumn{2}{c}{ Chợ Lách } \\
\cline { 3 - 6 } & & Hiệu chỉnh & Kiểm định & Hiệu chỉnh & Kiểm định \\
\hline 1 & $\Delta$ H đỉnh $(\mathrm{cm})$ & 3,00 & 3,60 & 7,70 & 9,90 \\
2 & $\Delta$ H đỉnh $(\%)$ & 2,05 & 2,44 & 4,90 & 6,25 \\
3 & $\Delta$ H chân $(\mathrm{cm})$ & 7,60 & 8,40 & 9,80 & 14,00 \\
4 & $\Delta$ H chân $(\%)$ & 5,15 & 6,18 & 8,31 & 13,00 \\
5 & NASH & 0,96 & 0,96 & 0,91 & 0,92 \\
\hline
\end{tabular}
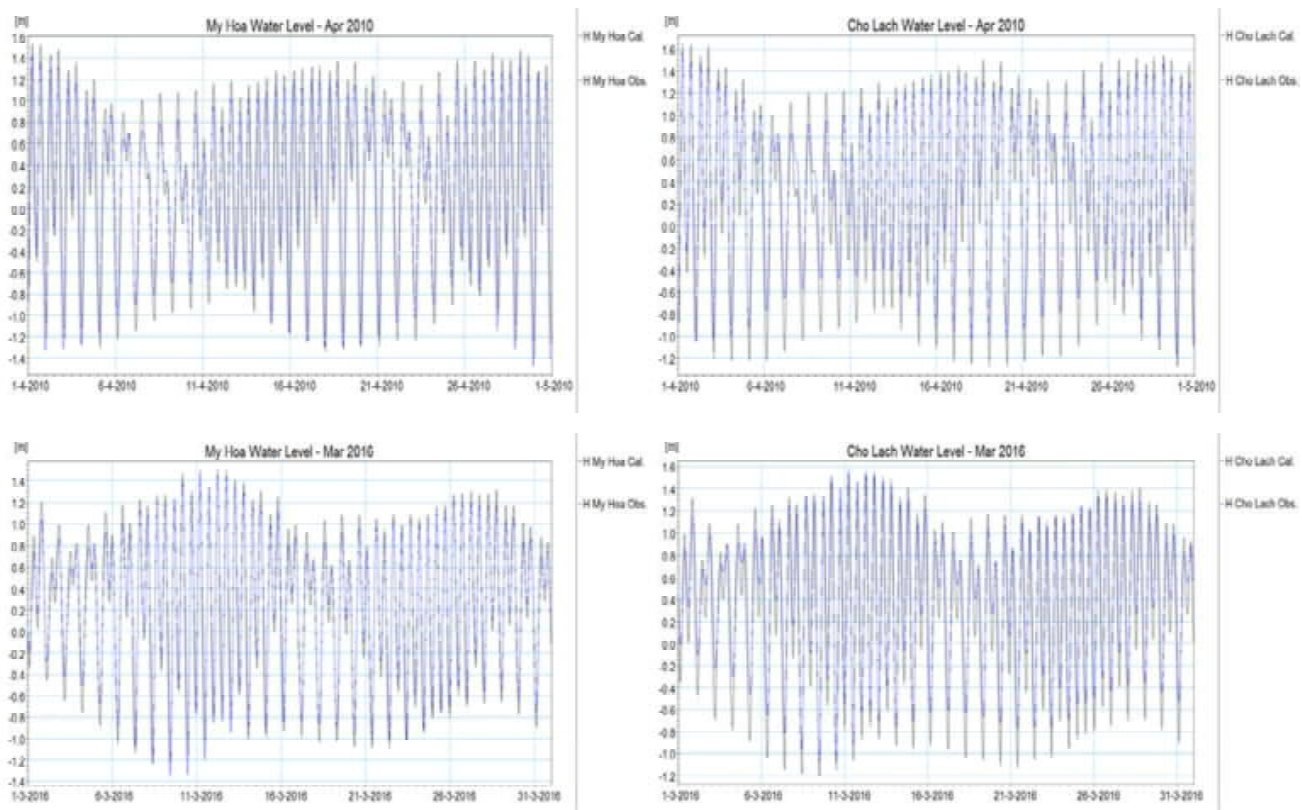

Hình 5. Kết quả đường quá trình hiệu chỉnh và kiểm định mực nước tính toán và thực đo tại Mỹ Hóa và Chợ Lách tháng 04/2010 và tháng 3/2016

Quá trình hiệu chỉnh, kiểm định mô hình thủy lực có thể thấy bộ thông số nhám đã cho kết quả khá tốt. Sự xuất hiện đỉnh và chân triều xảy ra đồng pha, hầu hết tại các vị trí kiểm tra đều tương đối phù hợp giữa tính toán và thực đo. Mô hình đạt loại khá với hệ số $\mathrm{NASH}$ thu được nằm trong khoảng từ 0,91 đến 0,96 , do đó sẽ được sử dụng cho các tính toán tiếp theo (Hình 5).

c) Hiệu chỉnh, kiểm định mô đun lan truyền chất

Dựa trên bộ thông số thủy lực đã ổn định, tiến hành tích hợp mô đun khuếch tán và hiệu chỉnh mô đun này cho số liệu đầu vào có thời gian tương ứng với tính toán thủy lực. Mạng lưới tính 
toán thủy lực được giữ nguyên và sử dụng cho tính toán khuyếch tán lan truyền mặn. Các thông số lan truyền chất được điều chỉnh bao gồm: Hệ số khuếch tán, hệ số mũ khuếch tán, thông số khuếch tán nhỏ nhất, thông số khuếch tán lớn nhất và điều kiện ban đầu. Thời đoạn hiệu chỉnh, kiểm định được sử dụng tương tự như đổi với mô-đun thủy lực. Kết quả thu được như sau:

Bảng 3. Thống kê các chỉ tiêu đánh giá kết quả hiệu chỉnh, kiểm định lan truyền chất

\begin{tabular}{ccccc}
\hline Trạm & Các chỉ tiêu & $\Delta$ S đỉnh $(\%)$ & $\Delta$ S chân $(\%)$ & Hệ số NASH \\
\hline \multirow{2}{*}{ Hương Mỹ } & HC & 0,69 & 0,32 & 0,8 \\
& KĐ & 0,87 & 0,52 & 0,71 \\
\multirow{3}{*}{ Sơn Đốc } & HC & 0,01 & 1,11 & 0,89 \\
& KĐ & 0,72 & 2,67 & 0,74 \\
\multirow{2}{*}{ Lộc Thuận } & HC & 0,71 & 0,07 & 0,79 \\
& KĐ & 0,18 & 1,51 & 0,71 \\
\hline
\end{tabular}
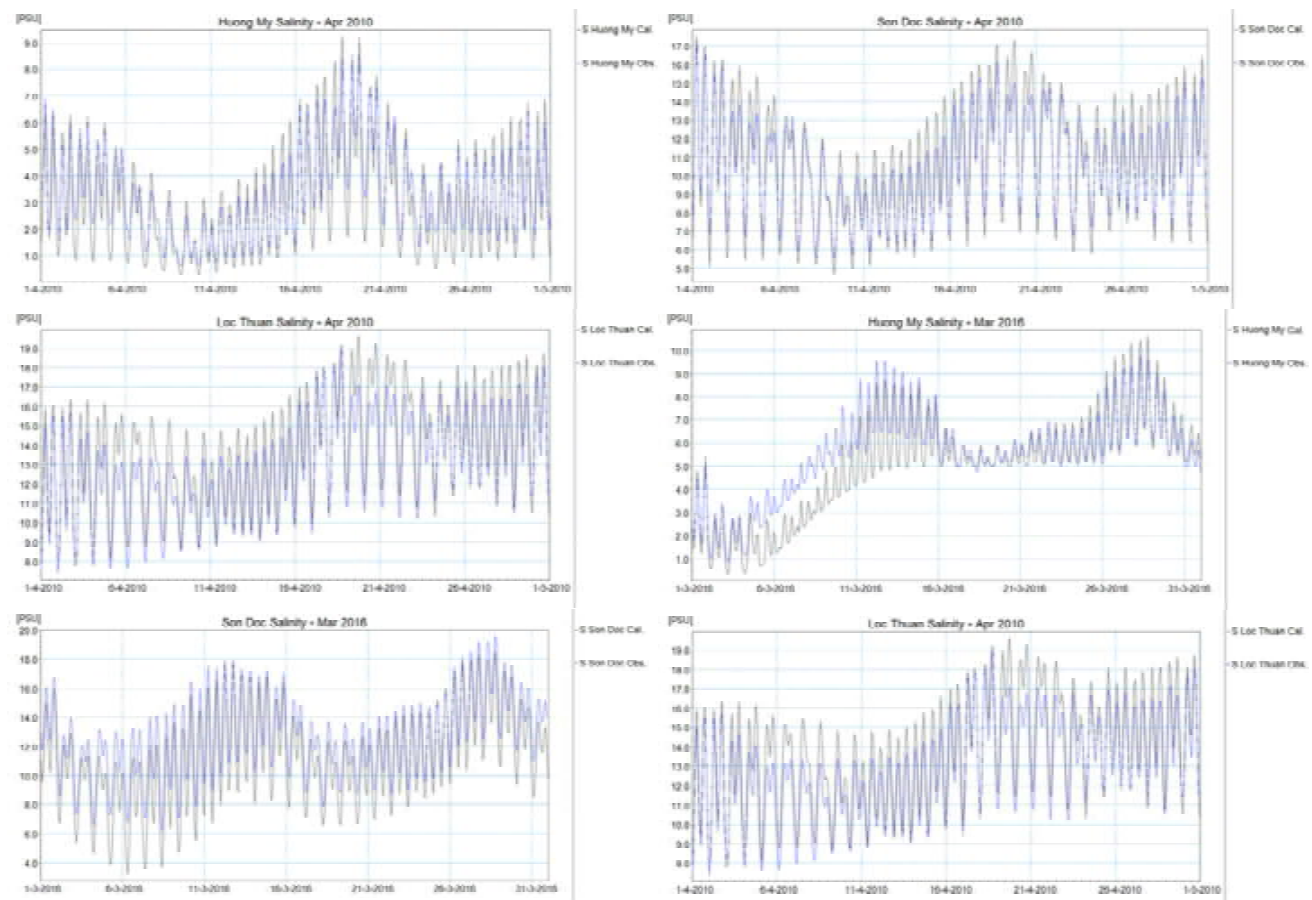

Hình 6. Kết quả đường quá trình hiệu chỉnh và kiểm định mặn tính toán và thực đo tại các trạm Hương Mỹ, Son Đốc, Lộc Thuận tháng 04/2010 và tháng 3/2016

Kết quả tính toán truyền mặn cho thấy, hầu hết tại các vị trí kiểm tra có đỉnh mặn tính toán và thực đo có sự phù hợp tốt, thời gian xuất hiện đỉnh tính toán không chênh lệch nhiều so với thời gian xuất hiện đỉnh mặn thực đo. Quá trình độ mặn tính toán và thực đo tại hầu hết các vị trí nhìn chung khá phù hợp (Hình 6). Các thông số cho mô đun khuếch tán đều nằm trong phạm vi cho phép của mô hình và có tính chất đặc trưng cho từng đoạn sông, từng cửa sông. Chỉ tiêu NASH cho các trạm đo mặn đạt giá trị khá và nằm trong khoảng 0,71-0,89. d) Mô phỏng xâm nhập mặn trong trong tương lai dưới tác động của $B Đ K H$

Để mô phỏng quá trình xâm nhập mặn trên các sông thuộc tỉnh Bến Tre, nghiên cứu tiến hành lựa chọn các kịch bản $\mathrm{BĐKH} \mathrm{[1]} \mathrm{phù} \mathrm{hợp}$ với khu vực nghiên cứu. Theo đó, 2 kịch bản được lựa chọn là $\mathrm{RCP} 4.5$ và $\mathrm{RCP} 8.5$. Mô hình đã được hiệu chỉnh và kiểm định ở trên được sử dụng để mô phỏng các kịch bản, trong đó các dự liệu điều kiện biên được thay đổi tương ứng dựa theo các kịch bản BĐKH (Hình 7). 


\section{BÀI BÁO KHOA HỌC}
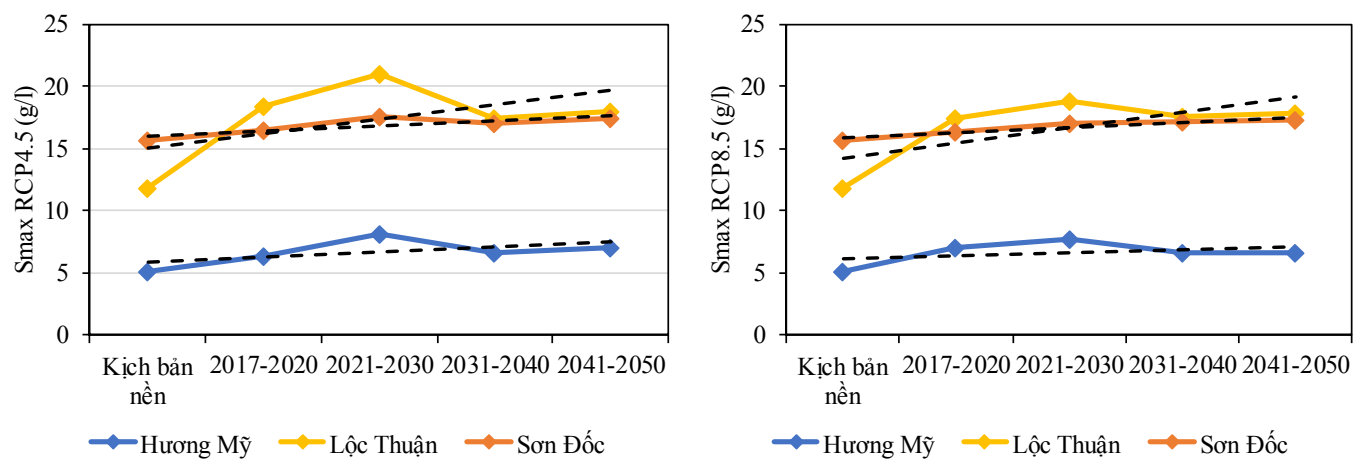

Hình 7. Diễn biến $S_{\max }$ tại một số trạm theo kịch bản RCP4.5 và RCP8.5

Bảng 4. Đặc trung $S_{\max }$ tại một số trạm theo kịch bản RCP4.5

(Đon vị: $g / l)$

\begin{tabular}{|c|c|c|c|c|c|}
\hline Trạm & Kịch bản nền & $2017-2020$ & 2021-2030 & $2031-2040$ & $2041-2050$ \\
\hline Hương Mỹ & 5,09 & $\begin{array}{c}6,30 \\
(+28,9 \%)\end{array}$ & $\begin{array}{c}8,12 \\
(+59,6 \%)\end{array}$ & $\begin{array}{c}6,59 \\
(+29,6 \%)\end{array}$ & $\begin{array}{c}6,99 \\
(+37,3 \%)\end{array}$ \\
\hline Lộc Thuận & 11,78 & $\begin{array}{c}18,33 \\
(+55,6 \%)\end{array}$ & $\begin{array}{c}20,99 \\
(+78,2 \%)\end{array}$ & $\begin{array}{c}17,46 \\
(+48,2 \%)\end{array}$ & $\begin{array}{c}17,99 \\
(+52,7 \%)\end{array}$ \\
\hline Sơn Đốc & 15,60 & $\begin{array}{c}16,52 \\
(+5,9 \%)\end{array}$ & $\begin{array}{c}17,61 \\
(+12,9 \%)\end{array}$ & $\begin{array}{c}17,03 \\
(+9,2 \%)\end{array}$ & $\begin{array}{c}17,41 \\
(+11,6 \%)\end{array}$ \\
\hline
\end{tabular}

Bảng 5. Đặc trung $S_{\text {max }}$ tại một số trạm theo kịch bản RCP8.5

(Đonn vị: g/l)

\begin{tabular}{|c|c|c|c|c|c|}
\hline Trạm & Kịch bản nền & $2017-2020$ & $2021-2030$ & $2031-2040$ & $2041-2050$ \\
\hline Hương Mỹ & 5,09 & $\begin{array}{c}7,05 \\
(+38,5 \%)\end{array}$ & $\begin{array}{c}7,68 \\
(+51,0 \%)\end{array}$ & $\begin{array}{c}6,57 \\
(+29,2 \%)\end{array}$ & $\begin{array}{c}6,60 \\
(+29,7 \%)\end{array}$ \\
\hline Lộc Thuận & 11,78 & $\begin{array}{c}17,38 \\
(+47,5 \%)\end{array}$ & $\begin{array}{c}18,79 \\
(+59,5 \%)\end{array}$ & $\begin{array}{c}17,52 \\
(+48,7 \%)\end{array}$ & $\begin{array}{c}17,84 \\
(+51,5 \%)\end{array}$ \\
\hline Sơn Đốc & 15,60 & $\begin{array}{c}16,38 \\
(+5,0 \%)\end{array}$ & $\begin{array}{c}17,05 \\
(+9,3 \%)\end{array}$ & $\begin{array}{c}17,08 \\
(+9,5 \%)\end{array}$ & $\begin{array}{c}17,34 \\
(+11,2 \%)\end{array}$ \\
\hline
\end{tabular}

Bảng 6. Khoảng cách tù cưa sông tới vị trí các nêm mặn ứng với các kịch bản BĐKH

\begin{tabular}{|c|c|c|c|c|c|c|c|c|c|}
\hline \multirow[b]{2}{*}{ Sông } & \multirow[b]{2}{*}{ Nêm mặn } & \multicolumn{4}{|c|}{$\mathrm{RCP} 4.5$} & \multicolumn{4}{|c|}{ RCP 8.5} \\
\hline & & §ิ & ণ্ণి & 옹 & ஜ̊ & ๙ิ & ণ్లి & 웜 & ஜ̊ \\
\hline \multirow{5}{*}{ Cổ Chiên } & $1 \%$ & 49,5 & 54,2 & 50,9 & 51,9 & 52 & 53,4 & 51 & 50,2 \\
\hline & $3 \%$ & 41,5 & 46,3 & 43,5 & 44,3 & 44,4 & 45,6 & 43,5 & 42,6 \\
\hline & $5 \%$ & 37,0 & 41,4 & 38,2 & 39,2 & 39,3 & 40,7 & 38,2 & 37,4 \\
\hline & $7 \%$ & 32,7 & 36,8 & 33,2 & 34,1 & 34,2 & 35,8 & 33,2 & 33,3 \\
\hline & $9 \%$ & 28,1 & 31,0 & 28,9 & 29,5 & 28,3 & 29,5 & 28,9 & 29,1 \\
\hline \multirow{5}{*}{ Hàm Luông } & $1 \%$ & 62,6 & 64,3 & 60,2 & 61,4 & 61 & 63 & 60,2 & 59 \\
\hline & $3 \%$ & 49,0 & 51,7 & 45,6 & 47,1 & 47 & 49,7 & 45,5 & 44,5 \\
\hline & $5 \%$ & 42,2 & 43,2 & 41,3 & 41,7 & 41,6 & 42,4 & 41,3 & 40,9 \\
\hline & $7 \%$ & 39,2 & 40,2 & 38,0 & 38,6 & 38,5 & 39,4 & 38 & 37,6 \\
\hline & $9 \%$ & 35,5 & 37,0 & 34,1 & 34,7 & 34,5 & 35,7 & 34,2 & 34,4 \\
\hline \multirow{5}{*}{ Tiền Giang } & $1 \%$ & 66,7 & 67,8 & 63,9 & 65,6 & 64,8 & 67,4 & 63,8 & 62,8 \\
\hline & $3 \%$ & 57,9 & 60,6 & 54,3 & 56,6 & 55,4 & 58,8 & 54,2 & 52,7 \\
\hline & $5 \%$ & 50,6 & 55,8 & 46,3 & 49,0 & 47,4 & 51,9 & 46,3 & 44,6 \\
\hline & $7 \%$ & 44,0 & 51,1 & 40,2 & 42,6 & 41,3 & 45,2 & 40,2 & 38,4 \\
\hline & $9 \%$ & 38,2 & 46,8 & 36,0 & 37,3 & 36,4 & 39,7 & 35,9 & 35,1 \\
\hline
\end{tabular}


Kết quả cho thấy ứng với cả 2 kịch bản BĐKH, mặn có xu thế tăng trên tất cả các trạm đo. Trong đó, cao nhất là trạm Lộc Thuận với đỉnh mặn trung bình thời đoạn lên đến 20,99\%o ứng với kịch bản RCP4.5. Giá trị này cao hơn $78,2 \%$ so với thời kỳ nền. Cửa Tiểu và Cửa Đại đồng thời cũng là 2 sông nhiễm mặn nặng nhất với mức tăng so với thời kỳ nền khoảng 48 78\% ứng với kịch bản $\mathrm{RCP} 4.5$ và khoảng 47 60\% ứng với kịch bản RCP8.5 (Bảng 4, Bảng 5). Theo đó, nghiên cứu tiến hành đánh giá mức độ ăn sâu nhất của các nêm mặn: 1\%o, 3\%o, 5\%o, 7\%o và $9 \%$ ứng với các kịch bản $\mathrm{BĐKH} \mathrm{(Bảng} \mathrm{6).}$

Có thể thấy, dưới tác động của $\mathrm{BĐKH}$ và nước biển dâng, mặn có xu thế ăn sâu hơn dọc các sông vào đất liền.

- Mặn 1\%o có khả năng ăn sâu vào 49 55 km trên sông Cổ Chiên, 59 65 km trên sông Hàm Luông, 62 68km trên sông Tiền Giang.

- Mặn 3\%o có khả năng ăn sâu vào 41 47 km trên sông Cổ Chiên, 44 52 km trên sông Hàm Luông, 52 61 km trên sông Tiền Giang.

- Mặn 5\%o có khả năng ăn sâu vào 37 42 km trên sông Cổ Chiên, 40 44 km trên sông Hàm Luông, 44 56 km trên sông Tiền Giang.

- Mặn 7\%o có khả năng ăn sâu vào 32 37 km trên sông Cổ Chiên, 37 41 km trên sông Hàm Luông, 38 52km trên sông Tiền Giang.

\section{Kết luận}

Qua các kết quả phan tích, nghiên cứu đã cho thấy trong giai đoạn 2000 - 2016, tình hình xâm nhập mặn tại tỉnh Bến Tre trong 6 tháng đầu năm có xu thế tăng ở hầu hết các trạm; tăng nhiều nhất ở trạm An Thuận, Bến Trại và Bình Đại (3 trạm cửa sông). Trong đó, sông Hàm Luông có xu thế xâm nhập mặn gia tăng nhanh nhất. Xét theo từng tháng, xu thế tăng được thể hiện chủ yếu, trong đó $100 \%$ trường hợp đỉnh mặn $\mathrm{S}_{\max }$ tăng; 91\% trường hợp chân mặn $\mathrm{S}_{\min }$ tăng, 3\% trường hợp $\mathrm{S}_{\mathrm{min}}$ giảm và $6 \%$ trường hợp không đổi. Xu thế tăng thể hiện rõ nét trong các tháng I, II, III; riêng xu thế giảm rất nhỏ đối với Smin thể hiện tháng $\mathrm{V}$ tại trạm Hương Mỹ nằm phía bên trong sông Cổ Chiên.

Úng với cả 2 kịch bản $\mathrm{BĐKH} \mathrm{(RPC4.5} \mathrm{và}$ RPC8.5), mặn có xu thế tăng trên tất cả các trạm đo. Trong đó, cao nhất là trạm Lộc Thuận với đỉnh mặn trung bình thời đoạn lên đến 20,99\%o ứng với kịch bản RCP4.5. Giá trị này cao hơn $78,2 \%$ so với thời kỳ nền. Cửa Tiểu và Cửa Đại đồng thời cũng là 2 sông nhiễm mặn nặng nhất với mức tăng so với thời kỳ nền khoảng 48 78\% ứng với kịch bản RCP4.5 và khoảng 47 60\% ứng với kịch bản RCP8.5. Nêm mặn theo đó cũng có xu thế ăn sâu hơn vào đất liền dọc theo tất cả các sông thuộc tỉnh Bến Tre.

\section{Tài liệu tham khảo}

1 Bộ Tài nguyên và Môi trường (2016), Kịch bản biến đổi khí hậu và nuớc biển dâng cho Việt Nam.

2 Nguyễn Tất Đắc (2007), Nghiên cưu xác định biên tính toán thủy lực và mặn cho ĐBSCL: Nghiên cứu xây dựng phần mềm máy tính áp dụng tính mưc nước, lư luợng, độ mặn cho ĐBSCL có tính tới biến đổi thượng lưu, gió chướng, nước dâng và thay đổi trên đồng bằng, Viện Khoa học thủy lợi Miền Nam.

3 Nguyễn Thị Thu Hằng (2009), Xây dụng chưong trình dụ báo xâm nhập mặn cho khu vưc đồng bằng sông Hồng - Thái Bình, Đề tài cấp Bộ.

4 Nguyễn Như Khuê (1994), Nghiên cứu về đặc điểm xâm nhập mặn của ĐBSCL, Viện Khoa học Thủy lợi Miền Nam

5 Nguyễn Ân Niên và Nguyễn Văn Lân (1999), Nghiên cứu xâm nhập mặn ở Việt Nam, Viện Khoa học Thủy lợi Miền Nam.

6 Lê Sâm (1993-2000), Dự án Khảo sát điều tra chua mặn ĐBSCL, Viện Khoa học Thủy lợi miền Nam, Bộ NN\&PTNT.

7 Trần Hồng Thái (2014), Nghiên cưu ảnh hưởng của BĐKH đến sụ biến đổi tài nguyên nước 


\title{
BÀI BÁO KHOA HỌC
}

Đồng bằng sông Củu Long.

8 Trung tâm Thẩm định-Tư vấn Tài nguyên nước, Cục Quản lý Tài nguyên nước (2012-2013). Đề tài cấp nhà nước Nghiên cứu cơ sở khoa học xác định nguyên nhân, đề xuất giải pháp ứng phó với xâm nhập mặn trong điều kiện Biến đổi khi hậu ở vùng đồng bằng sông Cửu Long.

9 UBND tỉnh Bến Tre (2018), Giới thiệu điều kiện tự nhiên, kinh tế xã hội tỉnh Bến Tre.

10 Viện Khoa học Khí tượng Thủy văn và Môi trường (2010), Dụ án "Đánh giá tác động của BĐKH lên tài nguyên nước và cá biện pháp thích ứng”.

11 Viện Khoa học Thủy lợi Miền Nam (2001-2004), Đề tài độc lập cấp nhà nước KC08-18 Nghiên cứu xâm nhập mặn phục vu phát triển kinh tế-xã hội vùng ven biển Đồng bằng sông Cưu Long.

12 Viện Khoa học Thủy lợi Miền Nam (2002), Đề tài độc lập cấp nhà nuoớc Nghiên cứu đề xuất các giải pháp KHCN phục vu xây dựng hệ thống đê biến, đê ngăn mặn cửa sông Nam Bộ.

13 Harleman D.R.F (1971), One dimensions estuarine modeling an assessment, Tracor, Inc, Project 16070DVZ, Water Quality Office, U.S Environmental Protection Agency, Stock No. 5501-0129, U.S Gorvement Printing, Office, Washington, DC.

14 Nguyễn Như Khuê (1986), Modelling of tidal propagation and salility intrusion in the Mekhong main estuarine system, Technical paper, Mekong Secretariat.

15 Leendertee (1971), Aspect of a computational model for long period water wave propagation, $R M$ - RC-5294, Rand Corp, Santa Monica, Califonia.

16 Prichard, D (1971), The dynamic structure of a coastal plain estuary, J. Mar. Res., 15, 33-42.

\section{EVALUATION OF THE SITUATION AND IMPACT OF CLIMATE CHANGE ON THE SALITY INTRUSION AT BEN TRE PROVINCE}

\author{
Nguyen Van Dao', Pham Thi Thanh Binh² \\ ${ }^{1}$ Hydro-Meteorology Survey Department \\ ${ }^{2}$ Center for Sea Survey and Mapping, Viet Nam Administration of Seas anh Islands
}

\begin{abstract}
Ben Tre is a coastal province, where there are 4 big estuaries flowing into the sea, so it is often affected by saline intrusion during the dry season. This study was conducted to evaluate the situation and assess the impacts of climate change (CC) and sea level rise (SLR) on saline intrusion in Ben Tre province according to various scenarios until 2050. Salinity measurement data from 2000 - 2016 of 6 salinity gauging stations in the province was analyzed to assess the saline intrusion in Ben Tre province. MIKE11 was used to simulate the saline intrusion under the impact of different climate change scenarios until 2050. The results show that in the period of $2000-2016$, saline intrusion in Ben Tre province in the first-half tends to increase in most stations. On a monthly basis, the uptrend is expressed mainly, and is clearly reflected in the months of January, February and March. Under the impact of climate change and sea level rise, salinity tends to intrude deeper along the rivers to the mainland. $1 \%$ salinity is capable of intruding nearly $55 \mathrm{~km}$ on Co Chien River, $65 \mathrm{~km}$ on Ham Luong River, $68 \mathrm{~km}$ on Tien Giang River; $5 \%$ salinity is capable of intruding up to $42 \mathrm{~km}$ on Co Chien River, $44 \mathrm{~km}$ on Ham Luong River, $56 \mathrm{~km}$ on Tien Giang River.
\end{abstract}

Keywords: Climate change, Sea level rise, Salt intrusion, Ben Tre Province, Modelling, MIKE 11. 